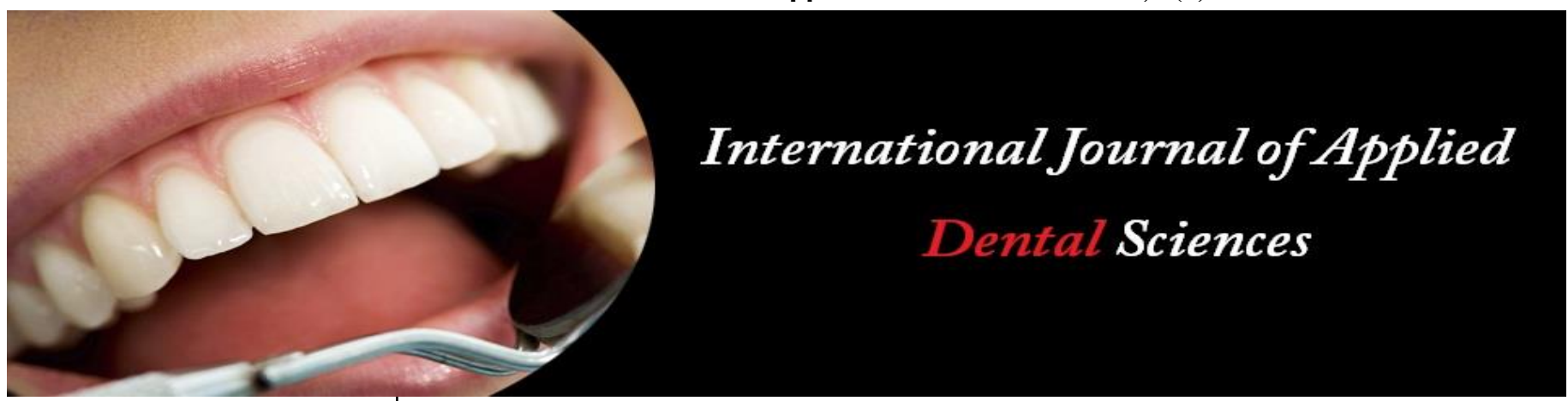

ISSN Print: 2394-7489

ISSN Online: 2394-7497

IJADS 2021; 7(1): 117-119

(C) 2021 IJADS

www.oraljournal.com

Received: 22-11-2020

Accepted: 27-12-2020

Dr. Amitoj Kaur Samra

BDS, SGRD Institute of Dental

Sciences and Research, Amritsar,

Punjab, India

Dr. Guriqbal Singh

BDS, SGRD Institute of Dental

Sciences and Research, Amritsar,

Punjab, India

\section{Different temporomandibular joint disorders and its prevalence in complete dentures patients: An observational study}

\section{Dr. Amitoj Kaur Samra and Dr. Guriqbal Singh}

DOI: https://doi.org/10.22271/oral.2021.v7.i1b.1127

Abstract

Aim: To determine the prevalence of temporomandibular disorders (TMD) in patients wearing complete denture (CD).

Material and Methods: This study was carried out SGRD Institute of Dental Sciences \& Research, Amritsar, India. 100 completely edentulous patients in the age group of 22-74 years who did not complain of any TMD and were denture bearers with a varied denture wearing span, were examined for the existence of TMD signs and symptoms were included in the study.

Results: Out of total 100 subjects examined, majority of the patients that is $28 \%$ fell in the age group of $50-60$ years, followed by $40-50$ years $22 \%$. There was no statistically significant association between different genders and age. The distribution of patients with or without TMD, 61.67\% males out of the total male subjects and $65 \%$ females out of total female subjects showed the presence of signs. The difference was found to be statistically insignificant. $42 \%$ of the subjects had 1-3 years of edentulous span followed by $32 \%$ with more than 5 years of edentulous span and $26 \%$ of the subjects showed 3-5 years of edentulous span. $34 \%$ of the subjects showed limited mouth opening as a sign of TMD followed by jaw deviation which is shown by $27(27 \%)$ of the subjects.

Conclusion: The most common finding was limited mouth opening while crepitus and clicking were least encountered.

Keywords: Temporomandibular dysfunction, temporomandibular joint, prevalence, denture wearer

\section{Introduction}

The phrase "temporomandibular disorders" grasps various clinical issues that include the muscles of mastication, the temporomandibular joint and related structures, or both. These are otherwise called temporomandibular pain dysfunction disorders ${ }^{[1]}$. Etiology of temporomandibular joint dysfunction (TMD) is multifactorial and may involve changes in occlusion (malocclusion in dentate and posterior occlusal wear producing incisal interference in complete denture [CD] wearers), faulty prosthesis (reduced vertical dimension), traumatic insult to TMJ, psychological components, and parafunctional habits such as bruxism ${ }^{[1-3]}$. Some predisposing factors which have been highlighted in recent studies are female gender and being edentulous for a long span of time without denture ${ }^{[1,4,5]}$. It has additionally been demonstrated that TMD changes over time, and no reasonable denouement has been arrived yet about its natural progression or about the factors contributing to the evolution of TMD. In addition, the quantity of individuals who see subjective manifestations or signs of TMD is more than the quantity of individuals looking for treatment, and females will probably look for treatment than male partners ${ }^{[6,7]}$. There are some controversial issues such as over closure of the jaws in persons with natural dentition which can predispose to TMD whereas long-standing edentulous span individuals without dentures rarely develop TMDs despite over closure. However, it is observed that edentulous individuals who do not gripe about TMD on an arbitrary examination may hint at least one or more signs of TMD, which may later form into a conspicuous joint dysfunction ${ }^{[3]}$. Some signs of TMDs are facial pain, headache, pain over the joint, pain which aggravates while opening the mouth, muscle tenderness of musculature, pain which is to the angle of lower jaw and cervical muscles, restricted mouth
Corresponding Author: Dr. Amitoj Kaur Samra BDS, SGRD Institute of Dental Sciences and Research, Amritsar, Punjab, India 
opening, deviation of jaw while opening the mouth, crepitus, and clicking sounds in joint region. These signs may appear in various combinations and degrees ${ }^{[3,4]}$. The role of occlusion to produce muscle spasm which may result in the above-mentioned signs does not apply to CD patients since malocclusion in dentures (e.g., centric prematurities) cannot trigger any proprioceptive response. Or maybe, quick after effect of centric prematurity is displacement of the denture which acts as a buffer to secure the TMJ ${ }^{[3]}$. The increase in the vertical measurement of dentures causes excessive extension of the jaw-closing muscles with increased pressure, which promotes TMD in edentulous individuals ${ }^{[8]}$.

\section{Material and Methods}

This study was carried out at SGRD Institute of Dental Sciences \& Research, Amritsar, India the period of 1 year.

\section{Inclusion criteria}

- Healthy asymptomatic TMD patients.

- Completely edentulous.

- Patients wearing CD.

\section{Exclusion criteria}

- Patients with a single CD with opposing natural teeth.

- Patient with partially edentulous arch.

\section{Methodology}

After taking informed consent detailed history was taken from the Participant. one hundred completely edentulous patients in the age group of 22-74 years who did not complain of any TMD and were denture bearers with a varied denture wearing span, were examined for the existence of TMD signs and symptoms were included in the study. The subjects were examined by a single trained clinician for the specific study.

\section{Statistical analysis}

The recorded data was compiled and entered in a spreadsheet computer program (Microsoft Excel 2010) and then exported to data editor page of SPSS version 19 (SPSS Inc., Chicago, Illinois, USA). Descriptive statistics included computation of percentages.

\section{Results}

Table 1: Out of total 100 subjects examined, majority of the patients that is $28 \%$ fell in the age group of 50-60 years, followed by $40-50$ years $22 \%$. There was no statistically significant association between different genders and age groups.

Table 2: shows that the distribution of patients with or without TMD, $61.67 \%$ males out of the total male subjects and $65 \%$ females out of total female subjects showed the presence of signs. The difference was found to be statistically insignificant.

Table 3: shows that $42 \%$ of the subjects had 1-3 years of edentulous span followed by $32 \%$ with more than 5 years of edentulous span and $26 \%$ of the subjects showed 3-5 years of edentulous span.

Table 4: summarized that majority of the subjects, i.e., 34 $(34 \%)$ of the subjects showed limited mouth opening as a sign of TMD followed by jaw deviation which is shown by $27(27 \%)$ of the subjects. The signs which are least shown were crepitus and clicking with respective $3 \%$ and $4 \%$.

Table 5: showed $42 \%$ of the subjects (25 males and 17 females) had a combination of two signs of TMD followed by $31 \%$ of the subjects showing only one sign and $27 \%$ of the subjects showing a combination of more than two signs.

Table 1: Age and gender distribution of patients

\begin{tabular}{|c|c|c|c|}
\hline Age in years & Males & Females & Total \\
\hline Below 30 & 5 & 3 & 8 \\
\hline $30-40$ & 12 & 7 & 19 \\
\hline $40-50$ & 13 & 9 & 22 \\
\hline $50-60$ & 18 & 10 & 28 \\
\hline $60-70$ & 7 & 6 & 13 \\
\hline Above 70 & 5 & 5 & 10 \\
\hline Total & 60 & 40 & 100 \\
\hline
\end{tabular}

$\chi^{2}=1.722, P\left(\chi^{2}>1.784\right)=0.9885$

Table 2: Distribution of patients with or without TMD

\begin{tabular}{|c|c|c|}
\hline Presence or absence of signs & Males (\%) & Females (\%) \\
\hline Presence of signs & $37(61.67)$ & $26(65)$ \\
\hline Absence of signs & $23(38.33)$ & $14(35)$ \\
\hline Total $(\%)$ & 60 & 40 \\
\hline
\end{tabular}

Table 3: Distribution of patients based on edentulous span

\begin{tabular}{|c|c|}
\hline Edentulous span (Years) & Number of subjects (\%) \\
\hline $1-3$ & $42(42)$ \\
\hline $3-5$ & $26(26)$ \\
\hline$>5$ & $32(32)$ \\
\hline
\end{tabular}

Table 4: Distribution of TMD sings in CD wearers

\begin{tabular}{|c|c|c|c|}
\hline Signs & Males (\%) & Females (\%) & Total (\%) \\
\hline Jaw deviation & $16(26.67)$ & $11(27.5)$ & $27(27)$ \\
\hline $\begin{array}{c}\text { Tenderness of masticatory } \\
\text { muscles }\end{array}$ & $10(16.67)$ & $6(15)$ & $16(16)$ \\
\hline Tenderness in joint & $9(15)$ & $7(17.5)$ & $16(16)$ \\
\hline Crepitus & $2(3.33)$ & $1(2.5)$ & $3(3)$ \\
\hline Clicking & $2(3.33)$ & $2(5)$ & $4(4)$ \\
\hline Limited mouth opening & $21(35)$ & $13(32.5)$ & $34(34)$ \\
\hline Total & 60 & 40 & $100(100)$ \\
\hline
\end{tabular}

$\chi^{2}=1.189, P\left(\chi^{2}>1.189\right)=0.9265$. TMD: Temporomandibular disorders. CD: Complete dentures

Table 5: Distribution of patients one or more sign of TMD

\begin{tabular}{|c|c|c|c|}
\hline Number of signs & Males (\%) & Females (\%) & Total (\%) \\
\hline One sign & $19(31.66)$ & $12(30)$ & $31(31)$ \\
\hline Two sign & $25(41.67)$ & $17(42.5)$ & $42(42)$ \\
\hline More than two sign & $16(26.67)$ & $11(27.5)$ & $27(27)$ \\
\hline Total & $60(100)$ & $40(100)$ & $100(100)$ \\
\hline
\end{tabular}
$\chi^{2}=0.023, P\left(\chi_{2}>0.023\right)=0.9764$. TMD: Temporomandibular disorders

\section{Discussion}

This study was conducted to determine the prevalence of temporomandibular disorders (TMD) in healthy without any symptoms completely edentulous patients wearing CD and to accomplish the relationship of TMD signs with edentulous span. Some studies have found that cases with $\mathrm{CD}$ with an increased prevalence of TMD symptoms in patients wearing $\mathrm{CD}$ than the individuals with natural dentition ${ }^{[9,10]}$. The present study showed that majority of the subjects have limited mouth opening which is in accordance with the studies done by researchers which have also found the lesser prevalence of TMD in CD wearers ${ }^{[11,12]}$. Our study showed that there was no significant difference between the number of males and females showing signs of TMD, however, some studies assessing TMD in dentate individuals, partial denture wearers, and $\mathrm{CD}$ wearers have found significantly more 
severe TMD signs and symptoms in females than in males [13-

15]. The present study showed more percentage of patients $42 \%$ with two signs of TMD followed by patients presenting with one sign $31 \%$. Which is in accordance with the studies conducted by Shetty and Al Zarea ${ }^{[12,13]}$. This study has also shown that majority of the subjects, i.e., 34\% showed limited mouth opening as a sign of TMD. Similar results were shown by some studies stating the reason of the muscular coordination needed to counteract relocation of the lower denture amid this exercise ${ }^{[11]}$. In our study, the least common finding was crepitus 3\% and clicking 4\%, however, Kirov and Krastev showed contradictory results and found joint sounds $(11.54 \%)$, muscle tenderness $(7.69 \%)$, joint tenderness $(5.77 \%)$, deviation of mandible $(3.85 \%)$, and limitation on mouth opening $(2.88 \%)$ in decreasing order of frequency ${ }^{[16]}$. The current study had shown that $63 \%$ of the subjects wearing CD showed the presence of signs of TMD which is in accordance with the results of the study conducted by Shi and Wang ${ }^{[14]}$. In our study majority of the subjects have shown an edentulous span of 1-3 years and there was a decreased trend of signs with increasing edentulous span which is in accordance with the results of $\mathrm{Al}$ Zarea ${ }^{[12]}$. The limitation of our study is that no standardized instrument or method was used to assess TMD prevalence and it did not differentiate TMD signs and symptoms. Future studies with larger study groups and standardized methods and instruments should be done to achieve proper conclusions.

\section{Conclusion}

With an increase in a number of patients wearing $\mathrm{CD}$, it becomes mandatory for dentists to be aware of the consequences of denture use over anatomy and physiology of TMJ to provide quality prosthodontics treatment. The most common finding was limited mouth opening while crepitus and clicking were least encountered.

\section{Reference}

1. Alzarea BK. Temporomandibular disorders (TMD) in edentulous patients: A review and proposed classification (Dr. Bader's classification). J Clin Diagn Res 2015;9:ZE06-9.

2. Rostamkhani F, Najjaran NT, Madani A. The relationship between temporomandibular disorders (TMDs) and overall denture conditions in complete denture wearers. J Dent Mater Tech 2015;4:101-10.

3. Shetty R. Prevalence of signs of temporomandibular joint dysfunction in asymptomatic edentulous subjects: A cross-sectional study. J Indian Prosthodont Soc 2010;10:96-101.

4. Kirov DN, Krastev DS. Prevalence of signs and symptoms of temporomandibular disorders in patients wearing complete dentures. Int J Sci Res 2014;3:947-9.

5. Shi Q, Wang YY. Investigation of the prevalence of temporomandibular disorders in 352 aged edentulous individuals. Zhonghua Kou Qiang Yi Xue Za Zhi 2012;47:19-21.

6. Witzel AL, Costa JE, Bolzan MC, Carli ML, Nunes TB, Di Matteo RC et al. Correlation between gender, temporomandibular joint disc position and clinical findings in patients with temporomandibular disorder. Med Express (São Paulo, Online) 2015;2:M150402.

7. Ahmed LI, Abuaffan AH. Prevalence of temporomandibular joint disorders among Sudanese university students. J Oral Hyg Health 2016;4:200

8. Monteith B. The role of the free-way space in the generation of muscle pain among denture-wearers. J Oral Rehabil 1984;11:483-98.

9. Mercado MD, Faulkner KD. The prevalence of craniomandibular disorders in completely edentulous denture-wearing subjects. J Oral Rehabil 1991;18:231-42.

10. Divaris K, Ntounis A, Marinis A, Polyzois G, Polychronopoulou A. Loss of natural dentition: Multi-level effects among a geriatric population. Gerodontology 2012;29:e192-9.

11. Al Shumailan YR, Al Manaseer WA. Temporomandibular disorder features in complete denture patients versus patients with natural teeth: A comparative study. Pak Oral Dent J 2010;30:254-9.

12. Al Zarea BK. Prevalence of temporomandibular dysfunction in edentulous patients of Saudi Arabia. J Int Oral Health 2017;9:1-5.

13. Shetty R. Prevalence of signs of temporomandibular joint dysfunction in asymptomatic edentulous subjects: A cross-sectional study. J Indian Prosthodont Soc 2010;10:96-101.

14. Shi Q, Wang YY. Investigation of the prevalence of temporomandibular disorders in 352 aged edentulous individuals. Zhonghua Kou Qiang Yi Xue Za Zhi 2012;47:19-21.

15. Shet RG, Rao S, Patel R, Suvvati P, Sadar LR, Yadav RD. Prevalence of temporomandibular joint dysfunction and its signs among the partially edentulous patients in a village of North Gujarat. J Contemp Dent Pract 2013;14:1151-5.

16. Kirov DN, Krastev DS. Prevalence of signs and symptoms of temporomandibular disorders in patients wearing complete dentures. Int J Sci Res 2014;3:947-9. 